\title{
Participatory Mapping of Disabled Access
}

Rob Kitchin Department of Geography $\mathcal{E}$ National Institute of Regional and Spatial Analysis National University of Ireland Maynooth, County Kildare, Ireland Rob.Kitchin@may.ie ". . access maps have large, potential utility."

“... many aspects of cityscapes remain inaccessible or difficult to navigate for people with mobility impairments . .."
In this paper, a rationale for a participatory approach to mapping is detailed, and its utility illustrated through the detailed reporting of a project concerned with mapping disabled access to the built environment. In this project, disabled people worked with university researchers at all phases of the research process, from formulation to data collection to end product, to create a detailed access map of their local town. The process of participatory research was found to be a rewarding and empowering experience for the disabled participants. Moreover the resulting map provides a significant resource for local disabled residents and has been important politically, being used to successfully lobby for changes to the local environment.

\section{Introduction}

$\mathrm{T}$ o date, with a few exceptions (e.g., Fry 1988; Vujakovic and Matthews 1994; and some progressive planning and state offices ${ }^{1}$ ), work relating to the production of maps for disabled people and disabled people's use of maps and mapping technology has almost exclusively concentrated on the design and development of tactile maps (Andrews 1988, Dodds 1989, Coulson 1991, Tatham 1991, Hinton 1993, Blades et al., 1999; Ungar 2000) and other navigation and orientation media for people with visual impairments (Golledge et al., 1991, 1989, Blenkham and Evans 1994, Fanstone 1995, Gill 1996, Petrie et al., 1996, Jacobson and Kitchin 1997; Jacobson 1998). As a consequence, while significant advances have been made in the development of the theory and practice (if not widespread application) of creating maps for people with visual impairments, there has been relatively little consideration given to maps that would facilitate and improve the interaction with the built environment for other disabled people, particularly those with mobility impairments. And yet, such access maps have large, potential utility.

Despite some improvements in the design of built environments in most Western countries, many aspects of cityscapes remain inaccessible or difficult to navigate for people with mobility impairments - paths are too rough for wheelchairs, there are steps but no ramps, doorways are too narrow, there are few if any designated parking spaces, public toilets are inaccessible, public phones are too high or in inaccessible booths, street furniture creates obstacle courses (these problems are acute in countries with weak planning legislation e.g., Ireland, but also in historic cities where preservation orders block architectural changes; Imrie 1996, Kitchin 2000a; see Figure 2 for examples). When some of these access factors have been addressed, it has often led to the creation of specific arrangements. For example, poor access to a building might be resolved by the creation of a specific disabled entrance rather than a modification of existing facilities. So as Napolitano (1995) and Imrie (1996) document, disabled entrances are often at the sides or backs of buildings, rather than at the front, along with access for everyone else. In other words, disabled people often still live in what Golledge (1993) calls 'transformed environments'. As a consequence, disabled people often have to take circuitous routes between locations, and have to plan to use alternative facilities if those provided are inacces- 
sible. For example, Kitchin and Law (2001) document how some disabled people structure their patterns of spatial behaviour around the location of accessible toilets. Such structuring is dependent on knowing where such toilets are actually located, and without detailed local knowledge this is often impossible, resulting in extremely restricted and routinised trips. An access map would be able to communicate such knowledge and also document the most accessible route between present location and the desired facility.

The project reported here aimed to examine the design and production of access maps for disabled people. However, rather than follow a conventional 'expert model' of cartographic enterprise, wherein the survey and mapping is undertaken by trained professionals, the project also aimed to explore the cartographic and political potential of adopting a participatory mapping approach. In doing so it aimed to explore and build on contemporary debates in disability studies about the nature of research concerning disability issues (see Barnes 1992; Barnes and Mercer 1997; Kitchin 2000b; Oliver 1992, 1999; Rioux and Bach 1994; Stone and Priestley 1996; Zarb 1992). In summary these authors argue, drawing in particular from feminist praxis, that the traditional division within research between expert and subject, researcher and researched, compounds the exclusion and marginalisation of disabled people in society, and assumes an expertise based on a perception of what it is like to be disabled. As a consequence, they argue that much disability research is not representative of disabled peoples' experiences and knowledges. Moreover, they contend that research concerning disability research is invariably researcher-orientated, based around the desires and agendas of (non-disabled) researchers rather than the subjects of the research (disabled people). Indeed, Oliver (1992) has gone so far as to argue that traditional research methodologies represent a 'rape model of research'. He argues that these research methodologies can be alienating, and disempowering to disabled people who take part in research. These participants place their knowledge into the hands of a researcher who then interprets and makes recommendations on the subjects' behalf. Oliver (1992) and others argue that the power-relations within the research process needs to be destabilized and the research agenda wrestled free from academic researchers so that it best serves the wishes of disabled people. As such, they call for the adoption of research strategies that are both emancipatory (seeking 'positive' societal change) and empowering (seeking 'positive' individual change through participation in the research process).

Such arguments about power in the research process and power conveyed in/through research outputs have also been voiced in the cartographic literature. For example, Harley's (1989) oft-cited critique reveals the fallacies of conceptualising and practising cartography as a scientific pursuit that is objective, rational, and value-free. Instead, Harley contends that mapping is a process of creating, rather than revealing, knowledge; creative decisions are made about what to include and what to exclude, how the map will look, and what the map is seeking to communicate (MacEachren 1995). As a consequence, maps are not objective, neutral artefacts but are imbued with the values and judgements of the individuals who construct them and pay for them (Harpold 1999). Maps are rhetorical devices; they are never merely descriptive, they are heuristic devises which seek to communicate particular, power-laden messages. Maps are thus situated, embodied and selective representations and while they might pertain to being objective, mimetic devises, they are ultimately constructed for particular purposes (Monmonier 1989) - they are (largely unacknowledged forms of) situated knowledges. Such a recognition of the
"... the traditional division within research between expert and subject, researcher and researched, compounds the exclusion and marginalisation of disabled people in society..."

"... mapping is a process of creating, rather than revealing, knowledge..."

"... maps are not objective, neutral artefacts but are imbued with the values and judgements of the individuals who construct them and pay for them ..." 
". . . the disabled people in the present project collectively owned, directed and controlled the study."

". . access maps provide valuable resources that can significantly improve daily interactions of disabled people with their local environments." subjective and political nature of mapping acknowledges the legitimacy and power of maps not created by cartographic 'experts', and in the case below created by disabled people (see Vujakovic and Matthews 1994 for similar arguments).

As a consequence of these arguments, while an aim of the project reported here was to develop a standardised symbol set for the creation of access maps and to test their utility, it also sought to explore the political potential of the research approach to create empowering and emancipatory geographies. In this latter regard, the study sought to build on other participatory studies undertaken by geographers (e.g. Anderson and Kitchin 2000; Kitchin and Mulcahy 1999; Routledge 1996; also special issue of Ethics, Place and Environment 2000) and in particular the work of Vujakovic and Matthews (1994). In their project they sought to incorporate the values of wheelchair users into the production of access maps of Coventry (United Kingdom). Here, there was an attempt to find out from disabled people what access issues exist, how such issues affect cognitive map knowledge, what should be included on an access map, and the form that the access map should take. Wheelchair users, paired with students who had cartographic training, were used as consultants. While the work reported here is similar, there are a number of differences. For example, the disabled people in the present project collectively owned, directed and controlled the study. They were trained and involved as much as possible in the design, creation and dissemination of the work. Several other differences are that the project aimed to produce a much more detailed access map for dissemination, and that the project also included people with a wider range of sensory and physical impairments. In other words, the project extended the emancipatory and empowering qualities of the Vujakovic and Matthews (1994) study by adopting a more inclusive, participatory stance at all stages of the project.

\section{The Project}

In the Republic of Ireland the only pieces of legislation related to accessibility are the 1990 Building Control Act, and Parts M of the Building Regulations 1991 and 1997. This legislation is tokenistic, weak and very poorly enforced. This ineffectiveness has recently been acknowledged by the Irish government which has published a consultation document acknowledging the failure of the legislation and condemning those who have used the 'reasonable provision' clause to make provisions for minimum access (Department of Environment and Local Government, 1999). In short, the legislation has had a minimal effect on access for disabled people to the built environment, invoking slow and ad hoc change in the landscape. As such, the buildings and public spaces are largely inaccessible and difficult to navigate. The result is that the $12-15 \%$ of the Irish population that are disabled do not enjoy the same freedom to independently undertake daily activities, such as visiting the shops or going to the pub, that non-disabled people take for granted. In these circumstances, access maps provide valuable resources that can significantly improve daily interactions of disabled people with their local environments.

It is in this context that the participatory mapping project was initiated in collaboration with the Newbridge Access Group (NAG). Formed in 1997, NAG is a pan-disability organisation that has campaigned with some success for better access in Newbridge, County Kildare (population 13,363 , OCPS 1996). In essence the aims of the project were (1) to undertake a detailed access audit of the town, (2) to produce an access map that residents and visitors could use to help effectively navigate and enjoy the 
town, (3) to lobby local politicians for change, and (4) to create a knowledge and skills base so that the disabled participants could repeat the exercise with other access groups to set up their own mapping projects. The project consisted of eight phases, each aimed to adhere to the principles of inclusive participation: that the planning, execution, and control of the project was agreed collectively.

The first phase consisted of planning the remit and scope of the audit. Three meetings were held to identify the nature of the project, the project's aims, and the process that would be employed. Once an initial plan had been formulated, the second phase was initiated. Phase two consisted of the formation of a subcommittee of four to consider and plan the specific and structural details of the audit. Here, the initial task was to develop a symbol set that would be sufficient to represent all situations and impediments that a disabled person (with either a physical or sensory impairment) might encounter while moving through the environment (see Figure 1). The symbols chosen had to be easy to apply to base maps while in the field (at 1:1250 scale, the most detailed base maps available), had to be easy to recognize, had to represent all types of impediments, and had to be transferable so that groups in other towns could also use them. As a guide, the sub-committee considered symbols used on other projects (e.g. Fry 1988, Vujakovic and Matthews 1994, Stadt Innsbruck n.d.), subsequently adopted some symbols, modified others, and where necessary, designed
". . . the initial task was to develop a symbol set that would be sufficient to represent all situations and impediments that a disabled person might encounter while moving through the environment."
SURFACES
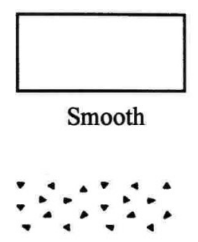

Rough

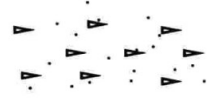

Gradient/Semi-rough

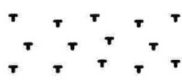

Tactile Surface

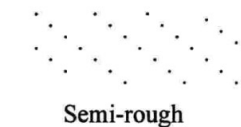

Semi-rough

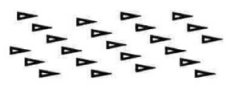

Gradient (arrows in direction of slope)

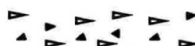

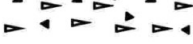

Gradient/Rough

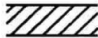

No path

PARKING/CROSSINGS

Designated Space
Undesignated Space
Dishing
Dishing/Lip
No Dishing
Pedestrian Crossing (Zebra)
Dishing but no crossing (with time)
No dishing/No crossing

Figure 1. Symbols employed in Newbridge map

ON PAVEMENT

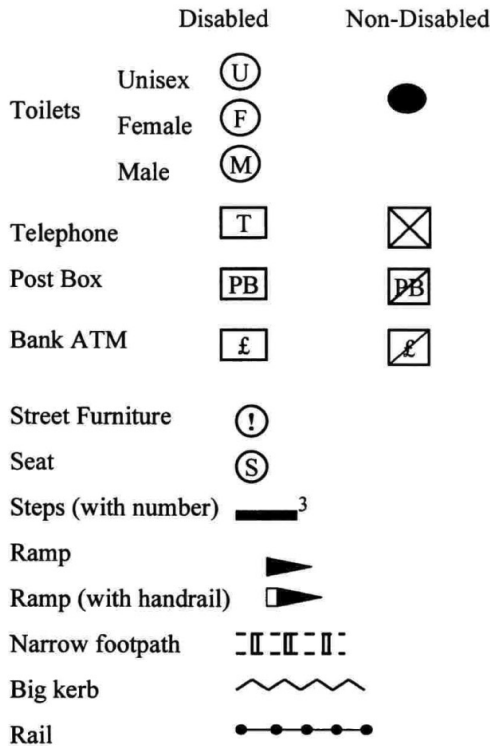

OFF-PAVEMENT

Single swing door

Double swing door

Narrow door

Electric door

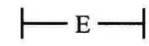

With steps Steps inside Steps or Lip outside/steps inside
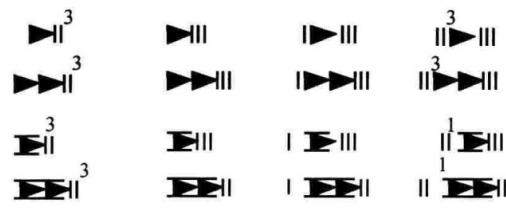
"From this pilot study, several new symbols were added to the set in response to some unanticipated impediments in the environment, and some of the symbols were revised because they were too difficult to apply to the map in the field." new symbols. Although the audit was to consider only the spaces between buildings and entries, a set of symbols for the inside of buildings was also developed. Next, it was decided which areas of the town would be surveyed, and possible strategies for dividing the work between the group's members. The last task in this phase was deciding the areas to be surveyed and mapped. The main shopping and civic areas were selected as study sites, and the region of study was divided into four, roughly equal sized survey areas.

The third phase entailed a pilot study to assess, using a small subsection of the town, the effectiveness of the symbol set. From this pilot study, several new symbols were added to the set in response to some unanticipated impediments in the environment, and some of the symbols were revised because they were too difficult to apply to the map in the field.

The fourth phase consisted of a training session to teach the members of NAG basic map reading, to illustrate how to recognize all environmental impediments, and how to apply symbols to the field map. This training session took place in the field so that members had guided experience in the environment, and so that they understood how to perform the necessary tasks. Members were instructed to follow the full survey procedure and place all relevant data - every doorway, every piece of street furniture, every public utility - onto the field map regardless of whether there were any access problems. This allowed a subsequent check for problems of cluttering, and to therefore determine how these problems might be addressed. The training session was followed by a de-briefing session during which participants discussed their field mapping experiences, and they provided suggestions for how the survey could be improved

The actual survey itself was the fifth phase. In total, eight disabled people performed the field survey. Group members were divided into four pairs, each pair assigned to one of for study areas. Each pair were supplied with enlarged A3 maps (originally scaled at 1:1250 at A4) of their designated area, along with a tape measure for measuring the width of doors and heights of curbs, and a camera. The camera was used to document particular problems encountered (see Figure 2). Progress was relatively swift, with the designated areas mapped within a couple of hours. Afterwards a de-briefing session occurred to make sure the survey was complete, and to compare notes about how well the survey had gone, and to identify any problems encountered.

Using the data collected, the sixth phase of the study consisted of producing high quality access maps suitable for distribution. Because of its labour intensive nature, this was the only phase not undertaken in collaboration with NAG (although NAG was consulted throughout). The maps were produced in the geography department at the National University of Ireland, Maynooth. Rather than use a specialized GIS package to produce the maps, a technique was developed that could be used by someone with access to a basic PC, using widely distributed software. In the end, each survey base map was scanned, and the symbols were then placed on the map using Microsoft's Powerpoint. Due to the thoroughness of the survey, the final access map was highly detailed, with all doorways, utilities, street furniture, path/road surface condition included. A portion of of the access map is shown in Figure 3. The full access map and photographs can viewed at: http://www.may.ie/staff/rkitchin/newbridge.htm

The seventh phase first entailed group members checking their survey maps against the final access map, and then a field check of the access maps in the environment itself was conducted to eliminate as many mistakes as possible. To perform a consistent field check, one group member that was not involved in the initial data collection process resurveyed the 

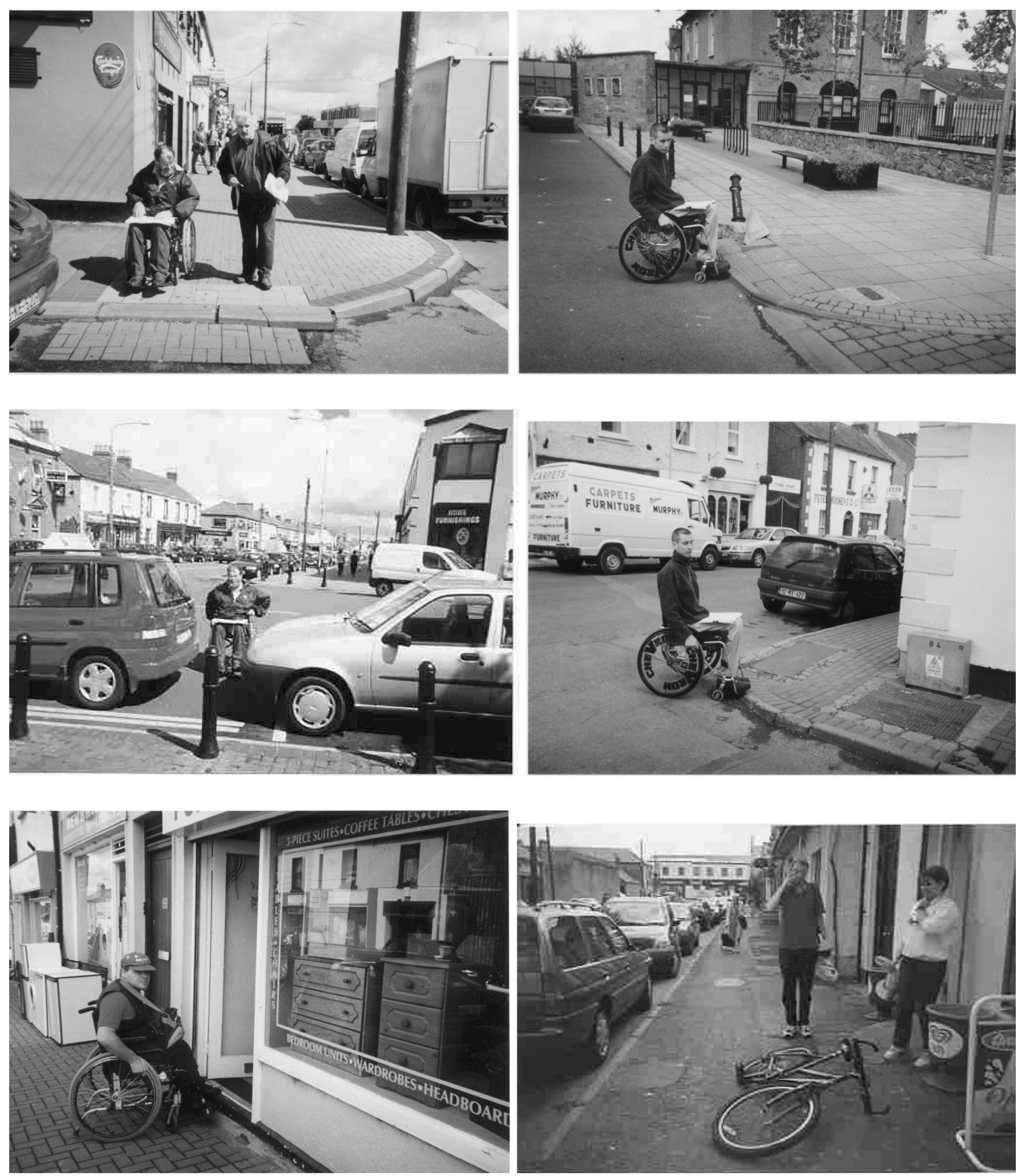

Figure 2. Undertaking the audit and some problems encountered 


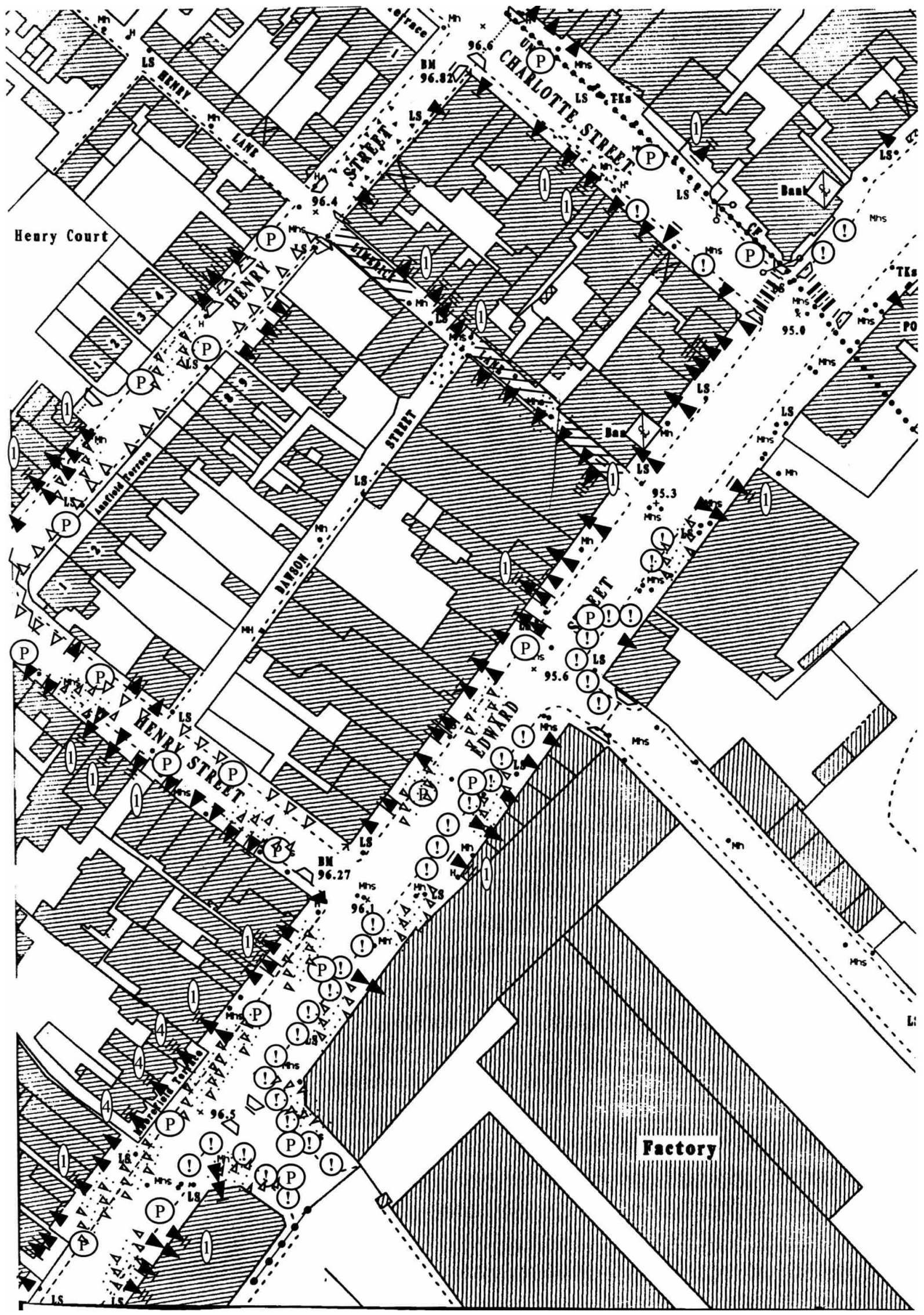


town using the final access map.

The eighth and final phase of the project was the publishing of the access map and its symbol set on the Internet via a series of Web pages. The Web page employs a simple user interface that allows the user to pan the access map. A series of hotspots embedded in the Web map enable the user to click on locations to see photographs illustrating the access problem at that location. In total, 25 photos were included on the web site and a sub-sample are shown in Figure 2. In addition, a large poster showing the entire map and a sample of the photographs was produced, and has been displayed at several locations around the town, and has been displayed at different community events.

In sum, the maps reveal that much of Newbridge is largely inaccessible to disabled people travelling independently. Scores of shops have entrances with steps or lips, and many premises are located upstairs. Disabled toilets are few and far between, facilities such as cash machines, post boxes and telephones are too high, and there are few designated parking places. Where there have been attempts to improve access by dishing the pavement, this has been done inadequately so that a lip remains. Indeed, the latest re-paving and make-over of the town has been very poorly executed, to the extent that features designed to aid access often fail in their aims.

\section{Conclusions}

The Newbridge participatory mapping project was considered a success by the participants in three main respects. First, the maps provide a detailed picture of access in the town and constitute a valuable resource for disabled residents and visitors. Second, the maps have been useful as a political devise for seeking change. While development has been slow, new public buildings are now generally adhering to ideas of universal access, and the issue of disabled access is now recognised by many local politicians. Third, the project has revealed the potential of a participatory research approach as an empowering and emancipatory strategy. While time consuming (yet relatively in-expensive), it was felt that the additional benefits of collective ownership and training added significant value to the project, without undermining the quality of the finished product. Moreover, because the map is based on firsthand experience of disabled people living in the environment, it is more representative of what access issues actually exist.

Furthermore, the project illustrated the rhetorical nature of mapping and the situated, embodied and selective nature of maps themselves by revealing the role of power in the mapping process and how power is expressed through maps. The collective and participatory approach explicitly challenges accepted conventions about who can legitimately creates maps, using what process, and for what audience. Further, it questions what messages are deemed to be important by State cartographers by illustrating the silence concerning disabled access communicated by conventional maps (and the power of that silence in reproducing inaccessible environments). Alternatively, the access maps created by NAG reveal a powerful message of exclusion by demonstrating the widespread inaccessibility of Newbridge's landscape. Such maps can be (and have been in NAG's case) used to lobby local politicians for planning reform because they provide tangible, 'scientific' proof of exclusions. Because of its empowering and emancipatory qualities, and the challenges it poses
". . the maps reveal that much of Newbridge is largely inaccessible to disabled people travelling independently."

". . the maps have been useful as a political devise for seeking change."

\footnotetext{
"The collective and participatory approach explicitly challenges accepted conventions about who can legitimately creates maps, using what process, and for what audience."
} 
NOTES for conventional cartography, participatory mapping is an approach that merits further investigation.

For example:

Stadt Innsbruck, n.d.;

Access Melbourne - http:/ /www.accessmelbourne.vic.gov.au/ Geelong CBD mobility map - http:/ /www.bdrc.org.au/map.htm Deakin University Mobility Maps - http://www.deakin.edu.au/maps / disabled_access /

Disabled Access Map - Penrith - http:/ /www.penrithcity.nsw.gov.au/ maps/mobility.htm University of Arizona, Tucson, Accessibility Map http:/ / parking.arizona. edu/Maps/disabled/Disabled.pdf

Anderson, P. and Kitchin, R.M., 2000. Disability and sexuality: Access to family planning services. Social Science and Medicine 51: 1163-1173.

Andrews, S., 1988. The use of capsule paper in producing tactile maps Journal of Visual Impairment and Blindness 79: 396-399.

Barnes, C., 1992. Qualitative research: Valuable or irrelevant?, Disability, Handicap and Society 7: 139-155.

Barnes, C. and Mercer, G. (eds.), 1997. Doing Disability Research, University of Leeds, Leeds: Disability Press

Blades, M, Ungar, S. and Spencer, C., 1999. Map using by adults with visual impairments. Professional Geographer 51: 539-553.

Blenkhorn, P. and Evans, D.G., 1994. A system for reading and producing talking tactile maps. Proceedings of the 9th International Conference on technology and persons with disabilities, California State University, Northridge.

Coulson, M.R.C., 1991. Tactile-map output from geographical information systems: the challenge and its importance. International Journal of Geographical Information Systems 5: 353-360.

Department of the Environment and Local Government, 1999. Consultation Document. Revision of Part M: Building Regulations. Dublin.

Dodds, A.G., 1989. Tactile maps: a psychologist's perspective. The Cartographic Journal 26: 3-6.

Ethics, Place and Environment, (special issue edited by R. Kitchen and R. Wilton), 2000. Geography, Disability and Ethics. 3(1): 61-102.

Fanstone, J., 1995. Sound and touch: a campus GIS for the visually impaired. GIS Europe, April: 44-45.

Fruchterman, J., 1995. Arkenstone's orientation tools: Atlas speaks and strider. Paper presented at Conference on Orientation and Navigation Systems for Blind Persons, Hatfield, UK, February 1-2.

Fry, C., 1988. Maps for the physically disabled. The Cartographic Journal 25: 
20-28.

Gill, J., 1996. An orientation and navigation system for blind pedestrians. MoBIC Consortium, Royal National Institute for the Blind, London

Golledge, R.G., 1993. Geography and the disabled: a survey with special reference to vision impaired and blind populations. Transactions of the Institute of British Geographers 18: 63-85.

Golledge, R., Parkes, D. and Dear, R., 1989. NOMAD: An auditory-tactile information system for blind or vision impaired travellers. NSF USA-Austrailia Cooperative Science Program, final report.

Golledge, R.G., Loomis, J.M., Klatzky, K.L., Flury, A. and Yang, X.L., 1991. Designing a personal guidance system to aid navigation without sight: Progress on the GIS component. International Journal of Geographical Information Systems 5: 373-395.

Harley, J.B., 1989. Deconstructing the map. Cartographica 26: 1-20.

Harpold, T., 1999. Dark continents: critique of Internet metageographies. Postmodern Culture, January 9(2).

http:/ / www.lcc.gatech.edu/ harpold/papers/dark_continents/index. html

Hinton, R.A.L., 1993. Tactile and audio-tactile images as vehicles for learning. Non-Visual Human Computer Interaction 22: 169-179.

Imrie, R., 1996. Disability and the City: International Perspectives. London: Paul Chapman Publishing.

Jacobson, R.D., 1998. Cognitive mapping without sight: Four preliminary studies of spatial learning. Journal of Environmental Psychology 18: 289-305.

Jacobson, R.D. and Kitchin, R.M., 1997. GIS and people with visual impairments or blindness: Exploring the potential for education, orientation and navigation. Transactions in Geographic Information Systems 2: 315-332.

Kitchin, R.M., 2000a. Disability, Space and Society. Geographical Association, Sheffield.

Kitchin, R.M., 2000b. The researched opinions on research: Disabled people and disability research. Disability and Society 15: 25-48.

Kitchin, R.M. and Law, R., 2001. The socio-spatial construction of disabledaccess toilets. Urban Studies 32: 287-298

Kitchin, R.M. and Mulcahy, F., 1999. Disability, Access to Education, and Future Opportunities. Combat Poverty Agency, Dublin, 32.

MacEachren, A.M., 1995, How Maps Work: Representation, Visualization, and Design. Guildford, New York.

Monmonier, M., 1991. How to Lie with Maps. The University of Chicago Press, Chicago.

Napolitano, S., 1995. Mobility impairment, in Hales, G. (Ed) Beyond Dis- 
ability: Towards an Enabling Environment. Sage: London, 30-35.

Office of Census and Population Surveys, 1996. Small Area Population Statistics. Dublin.

Oliver, M., 1992. Changing the social relations of research production. Disability, Handicap and Society 7: 101-114.

Oliver, M., 1999. Final accounts and the parasite people, in Corker, M. and French, S. (Eds) Disability Discourse. Open University Press, Buckingham. 183-191.

Petrie, H., Johnson, V., Strothotte, T., Raab, A., Fritz, S. and Michel, R., 1996. MoBIC: Designing a travel aid for blind and elderly people. Journal of Navigation, 49(1): 45-52.

Rioux, M. and Bach, M., 1994. Disability is not Measles: New Paradigms in Disability. North York, Ontario: L'Institut Roeher.

Routledge, P., 1996. The third space as critical engagement. Antipode 28: 399-419.

Stadt Innsbruck, n.d. Plan and Guide to Innsbruck for Disabled People. Map by Digitial-Kartographie.

Stone, E. and Priestley, M., 1995. Parasites, pawns and partners: disability research and the role of non-disabled researchers. British Journal of Sociology 47: 696-716.

Tatham, A.F., 1991. The design of tactile maps: Theoretical and practical considerations, in Rybaczak, K. and Blakemore, M. (Eds) Proceedings of International Cartographic Association: Mapping the Nations. London, ICA, $157-166$.

Ungar, S., 2000. Cognitive mapping without visual experience, in Kitchin, R. and Freundschuh, S. (Eds) Cognitive Mapping. Past, Present, and Future. London: Routledge, 221-248

Vujakovic, P. and Matthews, M., 1994. Contorted, folded, torn: environmental values, cartographic representation, and the politics of disability. Disability and Society 9: 359-374.

Zarb, G., 1992. On the road to Damascus: first steps towards changing the relations of disability research production. Disability, Handicap and Society 7: 125-138. 